\title{
LA EVOLUCIÓN DE LA INDUSTRIA GANADERA DE LIDIA ESPAÑOLA: UN ESTUDIO DE CASO A PARTIR DE LA GANADERÍA FUENTES (1798-1852)
}

Ricardo Ruiz Santamaría

Universidad de Cantabria

ruizsantr@unican.es

RESUMEN: La industria ganadera, en concreto la dedicada a las reses de lidia, comenzó a formarse a finales del siglo XVIII. Junto a ella apareció todo un mercado relacionado con el espectáculo taurino, desde los emplazamientos hasta los protagonistas, pasando por los ganaderos y apoderados. A la par de la búsqueda de réditos económicos, también aparecieron otro tipo de intereses muy distintos a los materiales, como el reconocimiento social, la fama y el ascenso dentro del statu quo. Uno de estos casos fue el de Julián de Fuentes, comerciante de origen riojano acomodado en Moralzarzal, donde formó una amplia ganadería de lidia que le trajo popularidad y reconocimiento en la primera mitad del siglo XIX.

Palabras clave: ganadería, Fuentes, mercado, toros, estatus social.

\section{THE EVOLUTION OF THE SPANISH BULLFIGHTING LIVESTOCK INDUSTRY: A CASE STUDY FROM THE LIVESTOCK FAMILY BUSINESS OF THE FUENTES (1798-1852)}

ABSTRACT: The livestock industry, specifically the one dedicated to bullfighting cattle, began to emerge by the end of the $18^{\text {th }}$ century. After that, it appeared a whole market related to the bullfighting spectacle, including locations, protagonists, ranchers and agents. However, along with this search for economic profit, another type of interests appeared that were very different from the material ones, such as social recognition, fame and promotion within the statu quo. One of these cases was that of Julián de Fuentes, a merchant from La Rioja 
settled in Moralzarzal, where he built a large cattle ranch which became very popular during the first half of the nineteenth century.

Keywords: Cattle breeding, Fuentes, trading, bulls, social status.

Recibido: 22 de junio de 2019 Aceptado: 16 de septiembre de 2019

\section{Introducción}

Uno de los espectáculos más atrayentes de la cultura ibérica es el conocido arte del toreo. En él, se aglutinan diversos aspectos que han identificado e identifican las formas de vida de los habitantes peninsulares, como son la ganadería y los espectáculos de masas. A pesar de la importancia social que tienen en la actualidad, este tipo de prácticas taurinas no comenzaron a profesionalizarse y a establecer a su alrededor un entramado económico hasta mediados del siglo XVIII. Si los juegos y entretenimientos taurinos en los escasos y puntuales festejos populares se habían surtido en parte gracias a la donación desinteresada de los ganaderos locales a los concejos; los encuentros taurómacos habían pertenecido de manera general a una cierta cultura elitista, imbricada en los torneos de exhibición caballerescos que por su naturaleza podía permitirse utilizar un alto número de ejemplares a través de la compra o la cría ${ }^{1}$. A finales del Siglo de las Luces, la ganadería de lidia se fue convirtiendo en un sector mucho más profesionalizado que en años anteriores, auspiciado por la alta rentabilidad de los espectáculos.

La conversión de este tipo de espectáculos en lo que hoy en día se conoce como "fiesta nacional" 2 solo se daría a partir del impulso y conformación de algunas sociedades filantrópicas como las Reales Maestranzas de Caballería ${ }^{3}$

1. Si bien es cierto que el espectáculo taurino como lo conocemos había comenzado a "popularizarse" desde finales del siglo XVII, la verdadera revolución taurina se produjo un siglo después, a partir de la profesionalización del toreo y la aparición de una serie de reglamentos que atañían a la novedosa realidad taurina. Amigo Vázquez, L., "El escenario de las fiestas taurinas. La plaza mayor como 'negocio' en la época moderna", Revista de Estudios Taurinos 24, 2008, pp. 118-141.

2. Término a debate entre múltiples sectores sociales a lo largo de estos dos últimos siglos. Shubert, A., "El toreo en la historia española", Revista de Estudios Taurinos 28, 2010, pp. 15-41.

3. López Martínez, A. L., El mercado taurino en los inicios de la tauromaquia moderna, Sevilla, Fundación Real Maestranza de Caballería de Sevilla y Universidad de Sevilla, 2013, pp. 45-81. Estas agrupaciones, formadas por miembros de la alta nobleza, respondían a una oligarquía urbana aficionada a los espectáculos animales. Tenían raigambre en los tradicionales torneos caballerescos medievales en los que la demostración de sus destrezas con la caballería ocupaba un espacio muy importante. 
del sur, la de Sevilla y Ronda, y, sobre todo, a partir de la concesión exclusiva por parte de la Corona para explotar estos espectáculos. Además de las Reales Maestranzas, la monarquía vio en estos acontecimientos una forma de sufragar los gastos de otras instituciones de carácter público como los Hospitales Reales. Así, les concedió también privilegios de arriendo sobre las corridas de toros y sus emplazamientos, lo que provocó que poco a poco se fueran estableciendo como un espacio de ocio cada vez más organizado y que se diese una profesionalización por parte de todos los miembros de los espectáculos.

De esta manera, las corridas de toros fueron desligándose de los espacios tradicionales como habían sido las plazas mayores de las ciudades, normalmente de forma cuadrada, creándose nuevos emplazamientos artificiales que acabarían dando lugar a las plazas circulares que se mantienen en la actualidad ${ }^{4}$. Las sociedades privilegiadas para explotar los festejos comenzaron a fomentar la construcción de ruedos permanentes, albergando ceremonias taurinas con cierta periodicidad y recibiendo grandes ingresos con cada una de ellas, tras haber arrendado el emplazamiento a iniciativas empresariales privadas. La creciente rentabilidad de estas diversiones incitó la llegada de nuevos empresarios al sector, que apostaron y lo convirtieron a finales del siglo XVIII en una parte más de sus redes de negocio. Además de la inversión en los espectáculos en sí, se aventuraron en la ganadería de lidia, condicionando de manera evidente tanto su forma de vida económica como su identidad cultural ${ }^{5}$.

Este trabajo pretende estudiar el fenómeno de la ganadería de lidia a través de un estudio de caso, el de la ganadería Fuentes ${ }^{6}$. De origen riojano, Julián de Fuentes adquirió, a finales del siglo XVIII, una serie de reses de casta jijona con las que construyó una importante ganadería de lidia, estableciéndose en Moral-

4. López Martínez, A. L., "Toros y urbanismo en España: plazas mayores, correderas y toriles", Revista de Estudios Taurinos 35, 2014, 15-58.

5. A finales del siglo XVIII y durante prácticamente todo el siglo XIX, el fenómeno del toreo se convirtió en el espectáculo de masas más importante para la sociedad española. Su lugar sería ocupado por otros en las primeras décadas del siglo XX, como los acontecimientos deportivos. Uría González, J., "El nacimiento del ocio contemporáneo", Historia Social 41, 2001, pp. 65-68.

Desde otras disciplinas sociales como la antropología, se han llevado a cabo diferentes estudios que demuestran la conexión entre los fenómenos de masas -en este caso, la tauromaquia- con las identidades culturales de las sociedades. Las teorías de J. MacClancy al respecto de la sociedad contemporánea española y la visión extranjera de ella, especialmente en aspectos como son el afecto, el ocio y la identidad política, permiten correlacionar las corridas de toros como uno de los argumentos básicos para demostrar sus teorías. MacClancy, J., "Falsificaciones inglesas del género, corridas y el Estado", pp. 125-137, en Fernández de Rota y Monter, J. A. (coord.), Las diferentes caras de España: perspectivas de antropólogos extranjeros y españoles, La Coruña, Universidad de la Coruña, 1996.

6. Este estudio se enmarca dentro de otro estudio mucho más amplio, que fija su interés en el ascenso social de la hidalguía rural en el contexto urbano, localizado cronológicamente desde finales del siglo XVIII y comienzos del XIX. 
zarzal y convirtiéndose en una de las más importantes de la sierra madrileña. La red comercial y los intereses sociales que influyeron en todas las decisiones concernientes a la ganadería supusieron un ejemplo del desarrollo económico y político en la incipiente y moderna industria taurina ${ }^{7}$.

\section{La ganadería de lidia: una expansión a demanda}

Los toros de lidia son descendientes de una especie desaparecida desde el medievo: el uro, un animal de grandes dimensiones y musculatura. Numerosos estudios han demostrado que al menos desde la Edad Media los ganaderos aplicaban de manera intuitiva técnicas de reproducción cruzada con esos animales para mejorar las cabañas bovinas ${ }^{8}$. Los cruces entre los mejores ejemplares de cada cabaña provocaban, de manera lógica, una mejora en los individuos, ampliando así también los réditos económicos del ganado a través de su venta o su aprovechamiento en labores de tiro. A través de estas técnicas intuitivas -prolongadas durante siglos- fue surgiendo una nueva especie, la del toro de lidia. Estas reses, de gran tamaño y carácter bravo como los uros, poseían grandes cualidades para la fecundación de las cabañas, y, además, servían para las cacerías o algunos juegos ${ }^{9}$.

De manera tradicional la ganadería bovina, y con ella la especie de lidia, se había desarrollado en las zonas del sur de la península, caracterizadas por sus amplias dehesas y pastos lejos de los núcleos de población. Las comarcas de la campiña de Jaén o las de la Vega del Guadalquivir fueron lugares predilectos para la cría y el incremento de estos ejemplares durante los siglos XVI y XVII ${ }^{10}$. Poco a poco, se fueron desarrollando ganaderías importantes, bajo la tutela de un grupo de ganaderos que habían ido concibiendo un método conocido como

7. López Martínez, A. L., La ganadería de lidia en España. Historia, Geografía y Empresa, Sevilla, 2018, pp. 36-45.

8. López Martínez, A. L, Ganaderías de lidia y ganaderos. Historia y economía de los toros de lidia en España, Sevilla, Fundación Real Maestranza de Caballería de Sevilla y Universidad de Sevilla, 2002, pp. 31-49.

9. Han sido numerosos los antropólogos que se han acercado a este fenómeno sociocultural ibérico. Las teorías sobre el origen y sentido de la tauromaquia han apuntado hacia la conexión inicial entre la Virgen María y la fiesta brava como un motivo de celebración de los ritos religiosos. El progreso y la estabilización de una red comercial propia permitiría celebrar estos festejos sin la necesidad de atender al calendario santoral. Pitt-Rivers, J., "The Spanish bullfight and kindred activities", Anthopology Today 9 (4), 1993, pp. 11-15.

10. López Martínez, A. L., "La cría del ganado de lidia y la gran explotación agraria en Andalucía (s. XVIII-XIX)", Estudios Agrosociales y Pesqueros 184, 1998, pp. 137-158. La ganadería bovina recibió en Andalucía la influencia directa de la agricultura. Ambas actividades se complementaban. La fuerza animal de los bóvidos era utilizada en tareas agrícolas, especialmente en la explotación del cereal. A pesar de esto, la ganadería bovina -sobre todo las grandes estabulaciones- quedaba reducida a un pequeño número de propietarios de tierras que podían permitirse alimentar a los animales. 
"tienta", del que se servían para determinar cuáles eran los mejores candidatos destinados a convertirse en sementales ${ }^{11}$. El método en sí consistía en un sistema de prueba sobre la bravura de los becerros, que distinguía -de manera muy ambigua y poco científica- a los más capacitados. No obstante, los ganaderos seguían buscando en estos animales una rentabilidad basada en su fuerza de trabajo y aplicación productiva, aunque pronto buscarían en ellos otros intereses relacionados con la tauromaquia.

Este desarrollo de las ganaderías andaluzas iba a la par también del impulso de los festejos taurinos en Andalucía. La aparición en el siglo XVII de algunas sociedades de nobles como las Reales Maestranzas de Caballería de Sevilla o de Ronda y su importancia como clase dominante, les permitió recibir en las primeras décadas del siglo XVIII el privilegio real de explotar estas festividades. Estas organizaciones surgieron en un momento de decadencia de la nobleza, como un intento por mantener su posición diferenciadora con respecto a los nuevos grupos sociales ascendentes, auspiciados por la riqueza económica cosechada por sus labores mercantiles.

Con la seguridad que aportaba la posesión del monopolio, las Reales Maestranzas fueron perfeccionando las ceremonias, construyendo plazas permanentes dedicadas de manera íntegra a la tauromaquia, y profesionalizando la industria $^{12}$. Este proceso, sostenido durante las primeras décadas del siglo XVIII, permitió extender la práctica de la lidia de manera ceremonial a la cultura popular, recibiendo cada vez más ingresos ${ }^{13}$. Se gestó en estos territorios del sur, por así decirlo, el embrión de lo que unos años después se trasladaría a todo el territorio peninsular, provocando que a mediados del siglo XIX existiesen más de medio centenar de plazas de toros en España ${ }^{14}$.

11. López Martínez, A., Ganaderías de lidia y ganaderos..., pp. 49-55.

12. La evolución de las plazas de toros tuvo mucha relación con el desarrollo de los entramados urbanísticos. Conforme se construían nuevos barrios en las ciudades, aparecían también elementos arquitectónicos de sociabilidad, como las plazas de toros. Las plazas de toros permanentes se convirtieron en una inversión desde finales del siglo XVIII por parte de sociedades empresariales, y tuvieron su auge en el siglo XIX, cuando comenzaron a responder a criterios urbanísticos planificados en zonas periféricas de la ciudad. Valle Buenestado, B., "Urbanismo y plazas de Toros", PH: Boletín del Instituto Andaluz de Patrimonio Histórico 49, 2004, pp. 39-45.

13. La historiografía ha demostrado que las festividades taurinas protagonizadas por el pueblo formaban parte de los entretenimientos populares desde el siglo XVI y XVII. Sin embargo, la profesionalización de este tipo de espectáculos no se dio hasta el siglo XVIII, lo que provocó que el ceremonial no llegase a estas diversiones hasta bien entrado el siglo de las luces. Guillaume-Alonso, A., "Las fiestas de toros en el Madrid crepuscular de Carlos II. Crónica de una evolución imparable", Revista de Estudios Taurinos 28, 2010, pp. 81-109.

14. A partir del último cuarto del siglo XVIII, la administración borbónica realizó un intento por controlar los espectáculos taurinos. Si bien durante la segunda mitad del siglo, Fernando VI había puesto empeño en prohibir aquellas corridas que no fueran benéficas; no fue hasta 1790 cuando Carlos IV, aconsejado por Godoy, promulgó una Real Orden por la que se 
Pero de manera paralela a la aparición del negocio, surgieron cada vez más interesados en él. En la segunda mitad del siglo XVIII, en Andalucía, creció ampliamente el número de personas dedicadas al negocio de la lidia. No solo eran ya las Reales Maestranzas con sus contratistas o los antiguos ganaderos poco especializados, sino que comenzó a surgir un número muy amplio de especialistas de todo tipo: tanto criadores de la especie de lidia como lidiadores profesionales. Con ellos también aparecían, cada vez con más fuerza, promotores de eventos que acabaron creando una red protoindustrial en torno a este fenómeno sociocultural.

La cría de lidia, ejercida tradicionalmente en la campiña andaluza, comenzó a expandirse a otros territorios peninsulares que, si bien no poseían los espacios más idóneos para la práctica, sí contaban con una amplia veteranía tanto en la ganadería de bóvidos como en la cultura de juegos taurinos. Eran zonas del norte, como la Canal del Ebro (Aragón y Navarra) o la Rioja Baja ${ }^{15}$, donde estos festejos tenían cabida durante las festividades patronales. Los concejos eran los organizadores, utilizando los espacios públicos como las plazas mayores o las calles para su práctica ${ }^{16}$. La afición de estas sociedades, sin embargo, no provocó que se diera en esas zonas una expansión económica tan grande como en las del sur, algo que impidió la creación de una industria taurina y con ella, una red ganadera similar a la de los territorios sureños.

Una realidad muy distinta también al caso andaluz fue la de la Villa y Corte, Madrid. No existían en la capital sociedades elitistas como las Reales Maestranzas, por lo que el devenir de la tauromaquia como arte fue llevado a cabo por otros protagonistas, aunque de manera similar. La monarquía borbónica, recién Ilegada a principios del siglo XVIII, repartió los privilegios de estos espectáculos a los Reales Hospitales a mitad de siglo, como forma de sufragar sus gastos. Estas organizaciones, copiando el ejemplo de las sociedades del sur, empezaron a formalizar las exhibiciones, construyendo una plaza en forma de circunferencia donde albergarlas. Al contrario que en Andalucía, las entidades madrileñas

prohibía realizar espectáculos fuera de las plazas, para más tarde, y aun bajo la influencia del Príncipe de la Paz, publicar una Real Pragmática en la que prohibía todo espectáculo taurino en el que se diese muerte al animal. La llegada de la Guerra de la Independencia provocaría la derogación de esta legislación.

Sánchez-Ocaña Vara, Á. L., "Las prohibiciones históricas de la fiesta de los toros", Arbor 189 (763), 2013, a074.

15. En La Rioja destacaron las zonas de Calahorra, Arnero o Alfaro, mientras que en Navarra era la ciudad de Pamplona la que más demanda de estas prácticas presentaba. La constancia de la cría de toros en el caso navarro era muy antigua, existiendo ya desde la Edad Media, pero, sin embargo, la caracterización física de las reses - de pequeño tamaño- hizo que fuesen apartadas del mercado comercial del espectáculo taurino.

Iribarren Rodríguez, J. M., "Los toros de Navarra", Príncipe de Viana 32, 1948, pp. 361-406.

16. Amigo Vázquez, L., "Fiestas de toros en Valladolid del XVII. Un teatro del honor para las élites del poder urbanas", Studia Histórica. Historia Moderna 26, 2004, pp. 283-319. 
decidieron arrendar el emplazamiento a iniciativas privadas: promotores que realizaban todo el trabajo de gestión (contratación de lidiadores y ganado y publicidad de los eventos) a cambio de un suculento alquiler ${ }^{17}$.

En un proceso muy semejante al andaluz, se fue construyendo durante las últimas décadas del XVIII un entramado comercial en torno al espectáculo taurino en la ciudad del oso y el madroño. Paulatinamente, la fiesta nacional se fue estableciendo como un espacio de ocio popular, cada vez más organizado y formalizado en las fechas, con un alto número de espectáculos anuales ${ }^{18}$. Pero la multiplicidad de estas celebraciones implicaba también una doble necesidad: por una parte, personas dedicadas al espectáculo taurino, aquellos a los que se conoce como toreros; por otra, animales con los que lidiar, lo que implicaba la aparición de vaqueros especializados en el sector.

Ambas necesidades eran de igual importancia, sin embargo, la segunda de ellas poseía una dificultad añadida ${ }^{19}$. Las zonas donde estaba extendida la ganadería de lidia, sobre todo Andalucía y zona media del Valle del Ebro, se encontraban a mucha distancia del centro peninsular y de la capital, algo que provocaba que el transporte del ganado fuese muy costoso, tanto desde el punto de vista económico como por el del tiempo empleado. Ante este vacío productivo en la ganadería de reses de lidia en la zona central de la península, y de manera casi orgánica, se crearon redes de mercado en la villa, apareciendo también los primeros ganaderos. Estos, sabedores del ímpetu que las masas aportaban a este tipo de espectáculos y la amplia demanda de ganado bravo, empezaron a desarrollar sus conjuntos ganaderos de bóvidos en zonas agrarias periféricas de la capital del reino, como la sierra norte madrileña o las zonas del sur como Aranjuez, donde se encontraba la Real Vacada Brava ${ }^{20}$. Las técnicas utilizadas, similares a las que habían empleado sus homónimos en la periferia peninsular, se vieron incrementadas en parte gracias al aprovechamiento del incipiente mercado ganadero de finales del XVIII, establecido en las ampliamente estudiadas ferias de ganado ${ }^{21}$.

17. López Izquierdo, F., "La Real Vacada Brava de Aranjuez: los toros más veces lidiados de Madrid", Villa de Madrid: revista del Excmo. Ayuntamiento 49, 1975, pp. 67-75.

18. López Martínez, A. L., La ganadería de lidia en España:..., pp. 20-24.

19. Es lógico entender aquí que las personas dedicadas profesionalmente a la lidia podían hacerlo durante un largo espacio en el tiempo, pero los animales dedicados a ello solo podían lidiar -en el mejor de los casos- dos veces, dada la naturaleza del espectáculo.

20. La Corona poseía una importante ganadería en las proximidades de la Corte, consciente de la necesidad de abastecer los espectáculos y juegos taurinos. Pero, además de ganado de lidia, la Real Vacada poseía también todo tipo de ganado, tanto bovino como ovino, con el que se proveían también los banquetes de la Corte.

López Izquierdo, F., "La Real Vacada Brava de Aranjuez: ...", pp. 67-75.

21. Delgado de la Cámara, D., "Las ferias toristas: Bilbao, Pamplona, Madrid", en Purroy Unanua, A. (coord.), V Jornadas sobre el Ganado de Lidia: Pamplona, 24 y 25 de noviembre de 2006, Pamplona, Universidad de Navarra, 2006, pp. 235-240. 
Así pues, a finales del siglo XVIII se había generado una oportunidad de negocio muy lucrativa, basada en el espectáculo de masas, con un mercado que no podía sino crecer $^{22}$. Conforme el espectáculo se iba profesionalizando, aparecía también una nueva forma de negocio que, además, proporcionaba prestigio y fama. Las figuras de las festividades: toros, toreros y ganaderos; los beneficiarios del espectáculo de masas: empresarios y promotores. El anuncio de los festejos era cada vez más amplio, a través de carteles publicitarios, que mostraban en primera plana las ganaderías que iban a participar, por encima incluso de los toreros. Los apoderados ejercían de negociadores entre promotores, ganaderos y toreros, en un sistema que se mantendrá hasta nuestros días ${ }^{23}$.

Este hecho no era baladí para los empresarios e inversores del país, que vieron una ocasión inmejorable para adentrarse en el mundo taurino. Uno de estos, entre otros muchos, sería Julián de Fuentes, conocido mercader de la capital que en 1797 comienza su andadura en la crianza del toro de lidia, a través de la compra de una ganadería vacuna procedente de Salamanca ${ }^{24}$. La búsqueda de rendimientos económicos junto con el prestigio social confluía en un negocio muy atractivo, siempre visto a largo plazo. Las élites económicas, las únicas capaces de sostener una inversión de amplia magnitud como esta, representaron indudablemente un papel protagonista en el desarrollo de la industria, sirviéndose de ello como trampolín para sus intereses sociales.

\section{La ganadería Fuentes (1798-1854)}

Natural de Valgañón, una pequeña aldea en la sierra riojana de la Demanda, y descendiente de un "hilandero" y ganadero ovino ${ }^{25}$, Julián de Fuentes emigró joven a Madrid en busca de fortuna y una mejora en la calidad de vida con res-

22. García-Baquero González, A., "Fiesta ordenada, fiesta controlada: las tauromaquias como intento de conciliación entre razón ilustrada y razón taurina", Revista de Estudios Taurinos 5, 1997, pp. 13-52.

23. Cabrera Bonet, R., "La iniciativa empresarial privada en el devenir del festejo madrileño del siglo XVIII", en García-Baquero González, A. y Romero de Solís, P. (coords.), Fiestas de toros y sociedad: actas del Congreso Internacional celebrado en Sevilla del 26 de noviembre al 1 de diciembre de 2001, Sevilla, Fundación Real Maestranza de Caballería de Sevilla, 2003, pp. 159-194.

24. Uriarte, L., El toro de lidia español, Madrid, Unión de Bibliófilos Taurinos, 1969. Las crónicas taurinas del momento apodaban al empresario como "El Indiano" por su amplia red de negocios con las islas Filipinas, dirigida desde Madrid junto con su socio José Martín de Ballesteros Pérez de Tagle, ambos pertenecientes al conglomerado empresarial de la Real Compañía de Filipinas. Archivo Histórico Provincial de Cantabria, Fondo Barreda, Casa Fuentes, Leg. 49-18. De aquí en adelante se utilizará la abreviatura AHPC para referirse al Archivo Histórico Provincial de Cantabria.

25. Los habitantes del Valle de Oja poseían desde 1312 la condición de hidalgos a partir del Fuero al Valle de Ezcaray, Ojacastro, Zorraquín y Valgañón. Fue confirmado en 1814 por Fernando VII. 
pecto a la localidad del Valle del Oja. A la crisis del sistema mixto económico serrano -textil y agrícola-característico de su pueblo de origen se sumaba una inexistente herencia: a pesar de que sus padres, Anastasio de Fuentes y Martina López Salces, eran personalidades notables en la aldea de Valgañón, mantenían una prole de siete hijos entre los que Julián ocupaba la segunda posición en la línea de sucesión ${ }^{26}$, y por la que, en base al sistema de mayorazgo, apenas recibiría una minúscula parte del patrimonio. Ante esta coyuntura, Julián decidió emprender su viaje hacia la capital del reino donde, como otros muchos, buscaba enriquecerse.

Así, aprovechando las redes de parentesco y paisanaje que tan bien han descrito algunos autores ${ }^{27}$, nuestro hombre comenzó a tejer un sistema mer-

Corral López, G., "Fuero de Valdezcaray: cinco siglos de privilegios (1312-1837)", Boletín A.R.G.H. 4, 2012, pp. 9-28.

Su abuelo paterno, Ángel de Fuentes, respondía como "hilandero y ganadero" a la trigésimo segunda pregunta del Catastro de Ensenada. Ángel de Fuentes, casado con $\mathrm{M}^{\mathrm{a}}$ Cruz de Porres, poseía una de las más amplias fortunas de los alrededores, siendo propietario de un rebaño de casi un centenar de carneros, además de una serie de pequeños terrenos, conocidos como "dehesas borreguiles" de los que, ante los condicionantes naturales, apenas rentabilizaba para el autoconsumo. Por este motivo, la actividad lanar tuvo mucha importancia en la zona, en especial la producción de paños y bayetas de baja calidad. La demanda textil se nutría sobre todo gracias a la llegada veraniega de ganado trashumante extremeño, y, por ende, desde mediados del siglo XVIII y el proceso de crisis mesteño, la economía local quedó ampliamente resentida. Para paliar esta situación, y en respuesta a la necesidad de un proyecto de futuro, la Corona decidió establecer en Ezcaray, a escasa distancia de Valgañón, la Real Fábrica de Paños de Santa Bárbara. Para su conformación, se aprovechaban de los batanes y calderas de tinte construidas antes, así como de un factor fundamental: la cercana fuerza motriz del río Oja. Moreno Fernández, J. R., "Las áreas rurales de montaña en la España del siglo XVIII, Las sierras del Sur de La Rioja", Revista de Historia Económica 19 (extra 1), 2001, pp. 66-79.

Archivo General de Simancas, Sección Catastro de Ensenada, Respuestas Generales de Valgañón, Leg. 057, 614-673. http://pares.mcu.es/Catastro/ (28-03-2019).

26. Toda la información referente a Julián de Fuentes y su hijo Juan José de Fuentes ha sido tratada a partir del Archivo Histórico Provincial de Cantabria, en concreto, a partir del Fondo Caja Cantabria, en su sección Familias, Casa Fuentes. En los legajos 35 y 36 se encuentra numerosa documentación sobre los menesteres ganaderos de dicha familia riojana, especialmente relacionado con los recuentos de ganado, libros de pagos y contratos con plazas de toros y otros ganaderos. Aun así, se echa en falta una mayor documentación que serviría para realizar una investigación mucho más completa -especialmente del primer período ganadero- de dicha empresa ganadera.

La historiografía especializada ha tratado el caso de esta ganadería de manera escasa, ante la falta de documentación relacionada en los principales archivos nacionales.

27. Es el caso de Jesús Cruz o Ángel Bahamonde, que han demostrado a través de sus investigaciones más importantes cómo se desarrollaban auténticas tramas mercantiles elaboradas a partir de relaciones de patronazgo. El caso de Julián de Fuentes, al igual que el de muchos hidalgos riojanos, está íntimamente ligado a la creación de la Real Cofradía de Nuestra Señora de Valvanera en 1723 e impulsada por Zenón de Somadevilla, Marqués de la Ensenada y riojano de nacimiento. 
cantil que le proporcionó en apenas una década una posición económica boyante ${ }^{28}$ con la que sostener una posición social digna de un hidalgo dedicado al comercio, siendo un miembro más de la sociedad madrileña. En el proceso de enriquecimiento se sirvió de la Real Fábrica de Paños de Ezcaray, una factoría creada en 1752 por iniciativa del gobierno ensenadista y que pretendía relanzar la economía lanera de la zona, en crisis tras el declive del fenómeno trashumante. A partir de 1785 fue controlada por los Cinco Gremios Mayores, compañía con la que Julián mantuvo relaciones comerciales y que le pondría en contacto con la Real Compañía de Filipinas, organismo del que formaría parte al menos desde 1790. Enrolado en las filas de dicha compañía, Julián de Fuentes sería enviado a Cantón, donde junto a Juan Martín de Ballesteros se convertiría en el factor mayor, responsable último del enclave comercial. Tras casi una década en tierras chinas, decidió volver a los territorios peninsulares, emprendiendo un ascenso social en el entorno de la Corte, aupado por una fortuna de casi cuatro millones de reales cosechada en los mercados orientales.

Su estatus social en la capital era similar al de otros tantos comerciantes descritos por diversos autores que han analizado esa época ${ }^{29}$. Sin embargo, el reconocimiento de la hidalguía universal norteña y una posición económica más que saneada no significaban que en la comunidad elitista madrileña se les respetase y tomase en cuenta como parte de la oligarquía. Ante esta situación, debían ser ellos mismos los encargados de granjearse fama y respeto entre las clases sociales más importantes de la villa madrileña, algo que, en el caso de Julián de Fuentes, pudo ver una salida dedicándose a la ganadería de lidia, una actividad de reciente creación profesional y que desde finales del siglo XVIII había ido tomando forma y abriéndose hueco en la actividad empresarial.

3.1. El inicio de la ganadería Fuentes: Julián de Fuentes y su ímpetu social (1798-1836)

Desde principios de la década de 1790 y en parte gracias a su legado paterno, Julián de Fuentes se dispuso a crear una cabaña ganadera de media casta, es decir, sin pureza de raza. El fomento de esta ganadería y la visión de negocio en

28. González Alonso, N. y Sánchez Gómez, M. A., "De la Sierra de la Demanda a la Corte. Un estudio de caso de la integración de las hidalguías antiguorregimentales en el sistema liberal", XVI Congreso de la Asociación de Historia Contemporánea, 2018. Las cifras que se manejan sobre la fortuna de Julián de Fuentes alcanzan, a fecha de 1798, los cuatro millones de reales de vellón, una cantidad más que considerable si tenemos en cuenta la coyuntura económica de esos años.

29. En el caso de los navarros, fue Julio Caro Bajo el encargado de demostrar su posición en la sociedad madrileña en "La Hora Navarra del XVIII", mientras que Jesús Cruz apuntó en "Los Notables de Madrid..." un estudio mucho más amplio sobre las bases sociales de la revolución liberal española, grupos sociales basados en sus fortunas. 
el mercado de toros de lidia provocó la compra, en 1798, de unos sementales de José Jijón, descendiente de una reputada ganadería de Villarubia de los Ojos, en Ciudad Real. Dichas reses poseían un tono colorado encendido, similar al pardo, además una complexión morfológica prominente ${ }^{30}$.

Ese mismo año, aprovechando el proceso desamortizador de Godoy sobre los bienes y propiedades Ilamados de manos muertas, Julián de Fuentes invirtió en zonas periféricas de la villa, especialmente en el municipio de Moralzarzal, al noroeste; un enclave en el que las prácticas ganaderas tendrían raigambre gracias a sus amplias superficies de pastizal ${ }^{31}$. La introducción de esta nueva especie en la zona, propia de lugares Ilanos como Salamanca o Jaén, causó una revolución en la forma de entender la ganadería en la sierra madrileña de Guadarrama. Pronto comenzaría a tener éxito, pues solo tres años después ya contaba con un pequeño número de novillos de la casta jijona, especie que caracterizaría a su ganadería ${ }^{32}$.

No sería hasta 1807, coincidiendo también con la obtención del título de regidor perpetuo de la villa de Madrid, cuando la ganadería de Julián de Fuentes pudo comenzar a rentabilizar la inversión realizada casi una década atrás. La minuciosa selección realizada por sus pastores, elaborada a través del proceso de tienta, había permitido poseer varios ejemplares bravos con los que podía establecerse como una ganadería taurina de relativa importancia en la capital.

La llegada de la Guerra de la Independencia, al contrario de lo que podría parecer, contribuyó a la evolución de la ganadería. Julián de Fuentes supo aprovechar la coyuntura socioeconómica y decidió invertir en el proceso de enajenación de propiedades comunales del concejo de Moralzarzal con los que se procuró sustentar el gasto de la guerra ${ }^{33}$. De esta manera, se hizo dueño de una serie de terrenos llanos muy cercanos a la sierra de Guadarrama, con amplios pastizales y que permitían

30. López Izquierdo, F., Historia del toro de lidia: de la prehistoria hasta nuestros días, Madrid, Agualarga, 1996, pp. 105-123. Dicha subespecie mostraba un aspecto físico superior al del resto de toros de su tiempo, con grandes cornamentas y grueso esqueleto. Estas características, además de su bravura, la convertían en una casta idónea para el toreo.

31. $A H P C$, leg. 47-10 y leg. 48-1. Se tiene constancia de la compra de varias fincas en la zona de Moralzarzal por parte de Julián de Fuentes, durante los últimos años del siglo XVIII, aprovechando el proceso de liberalización de la propiedad.

32. AHPC, leg. 60-9. Ese mismo año recibiría el título de Caballero de la Orden de la Espuela Dorada y Conde de Sacro Palacio por el Papa Pío VI, hecho que marcó su devenir en el status social durante las siguientes décadas y que le produciría grandes beneficios socioeconómicos.

33. Han sido numerosos los autores que han estudiado este fenómeno enajenador en las últimas décadas. La venta de terrenos comunales para sufragar los gastos de la Guerra de la Independencia fue un fenómeno bastante común en las zonas del norte peninsular. A pesar de que al regreso de Fernando VII se proclamaron leyes para censurar dichas ventas, la historiografía ha dejado constancia de la poca efectividad que tuvieron estos dictámenes.

Iriarte Goñi, I., "Common lands in Spain, 1800-1995: Persistence, Change and Adaptation", Rural history 13 (1), 2002, pp. 19-38. 
aumentar su ganadería no solo con reses bovinas, sino también añadiendo algunas cabezas de ganado ovino. Además, estableció una vivienda, denominada La Huerta, lugar desde donde controlaba las operaciones ganaderas ${ }^{34}$.

Durante el episodio bélico, apenas se pudieron mantener los gastos de la cabaña de los Fuentes. En el transcurso del período bonapartista, Julián de Fuentes se dedicó a controlar el ganado a través de su estabilización en Moralzarzal, manteniendo una posición política al margen de la evolución de los acontecimientos, en favor de sus intereses económicos ${ }^{35}$.

Si bien no era el ganadero de lidia más experto, Julián de Fuentes sí poseía una visión empresarial y una gran destreza en lo económico, derivada en gran parte de su experiencia comercial. Así fue como, en 1811, en mitad de la cruenta guerra, el riojano decidió vender su vacada original, que había comprado en Salamanca, a favor de la compra de reses de casta jijona. La raza, que tenía gran fama por su bravura, fue comprada a bajos precios, aprovechando la situación de crisis económica provocada por la Guerra de la Independencia ${ }^{36}$.

Además, tras la coronación de Fernando VII, supo valerse de su estatus también para recuperar la posición de regidor perpetuo conseguida unos años antes y avanzar en su proyecto ganadero, especialmente a través de las festividades taurinas celebradas en nombre del reinstaurado monarca. La plaza de Madrid, el 24 de mayo de 1814, requirió al menos cinco reses bravas de la ganadería Fuentes, aunque en las cláusulas contractuales no se hiciera referencia al precio de dichas reses $^{37}$. Sin embargo, la proliferación de espectáculos que se daría a partir del período restaurador provocó una subida en los precios durante los primeros años de la restauración borbónica, que convertiría a los ganaderos en los grandes beneficiarios del negocio, conformándose así lo que López Martínez ha vinculado a la "burguesía rural", profesionales del mercado taurino que demostraron su astucia en este negocio y que aprovecharon la desaparición de las ganaderías de carácter monástico y nobiliaria ante la coyuntura político-económica ${ }^{38}$.

34. AHPC, leg. 29-1 y 29-2. La disposición de este domicilio se compaginaba también con otros cuatro en el centro de la villa de Madrid, en las calles del Arenal y Alcalá, zona comercial por excelencia de los Cinco Gremios Mayores, sociedad con la que el riojano tenía mucha relación. El arrendamiento de algunos de estos domicilios le proporcionó amplias rentas durante el siglo XIX.

35. De la misma manera que invirtió su capital en la compra de terrenos de la sierra madrileña, también lo hizo en otras zonas cercanas ideales para la cría del ganado, como la zona conocida como la Encomienda de Biedma, situada en la actual Villarrubia de Santiago, cerca de los montes de Toledo. Como ha demostrado la historiografía, esta zona ha sido tradicionalmente utilizada para la ganadería por la calidad de sus pastos y buenos condicionantes climáticos. López Martínez, Antonio L., La ganadería de..., pp. 202-212.

36. Aragón, G. y Bollaín, J. A., Los Toros de la Tierra (primera parte), Madrid, Ed. Propia, 2017, p. 214.

37. Ibidem, p. 184.

38. López Martínez, A. L., La Ganadería de lidia en España..., pp. 46-48. 
En la campaña de 1817, la ganadería bovina de Julián de Fuentes contaba con setenta y cuatro cabezas cerriles y cincuenta y un toros de lidia, cifras más que respetables dentro de la comunidad ganadera bovina, si tenemos en cuenta la especificidad de dicha cabaña ${ }^{39}$. El alto número de toros brindó mucho éxito a la vacada, en especial en las pequeñas corridas patronales de Madrid y la Feria de Valladolid, a donde vendió ese mismo año casi una docena de reses.

Pero el mismo motivo del éxito provocó también una gran pérdida en la ganadería. El alto número de toros jijones vendidos a las plazas durante 1817 provocó también que el número de reses de lidia disminuyese mucho. A pesar de que los beneficios -tanto monetarios como sociales- habían sido muy amplios, la realidad de la ganadería en la campaña de 1818 era que contaba con menos de treinta toros de lidia. Durante las siguientes campañas taurinas pondrían en marcha una política de cría y compra de sementales para la vacada, un proceso a largo plazo que tendría sus resultados unos años después. En esta decisión, al "Indiano" le acompañaría ya su hijo, Juan José, quien sería después el heredero de la ganadería y de la fortuna Fuentes. Mientras Julián de Fuentes solapaba su cargo de regidor con el puesto en la Real Compañía de Filipinas, su hijo se encargaba de los asuntos de las propiedades en Moralzarzal y en la villa de Madrid ${ }^{40}$.

Tras unos primeros años de cría algo decepcionantes en cuanto a la bravura de las reses, Julián de Fuentes y su hijo, conscientes de su falta de experiencia y la gran atención que necesitaba la ganadería, decidieron contratar a mediados de la década a Antonio Balandín, un ganadero menor de Moralzarzal, para que actuara como apoderado suyo ${ }^{41}$. Le encargaron gestionar los asuntos de la cabaña y procurar la evolución en condiciones de bravura. Este apoderado mantuvo su puesto durante casi dos décadas, algo que propició la estabilidad deseada en el desarrollo de la vacada. El plan del moraleño no solo se basaba en de la cría, sino también en la compra de nuevos ejemplares en las ferias de ganado, como las de León o Zamora, criando hasta veintiséis bóvidos para la lidia, de raza jijona pura, en tan solo un lustro ${ }^{42}$.

39. $A H P C$, leg. 35-5. Junto a este volumen de reses, aparecía un pequeño número de novillos que se convertirían en futuros toros de lidia.

40. AHPC, leg. 36-4.

41. La tradición ganadera de la sierra madrileña no se centró tan solo en Moralzarzal, sino que se extendió a localidades serranas cercanas como Colmenar Viejo o Cerceda. Los estudios de López Martínez sobre la sierra madrileña como lugar de cría de ganado de lidia establecen a la localidad de Colmenar Viejo como la más fecunda en la labor, especialmente desde la segunda mitad del siglo XVIII.

López Martínez, A. L., La ganadería de..., pp. 197-202.

La ganadería Fuentes mantuvo relación con las ganaderías vecinas, especialmente a través de la compra y venta de terrenos de pasto para las reses. AHPC, 37-8.

42. AHPC, leg. 35-6. La documentación refleja diferentes negocios en dichas ferias, además de escritos contractuales de préstamo para la compraventa de diferentes toros de lidia. 
El ambicioso plan de los Fuentes giraba en torno a dos objetivos claros: el primero, alzar su fama entre las ganaderías y plazas de toda España a través de la pureza de su ganado; el segundo, establecerse como una familia de renombre en el panorama nacional. Durante finales de la década de 1820 y principios de la de 1830, junto con la estabilidad política del país, comenzó a aumentar el número de festejos y, con ello, las ventas de la ganadería. Para mantener su oferta taurómaca, la ganadería Fuentes mantuvo contacto con otros ganaderos locales, aprovechándose de las oportunidades que le prestaban algunas situaciones como la muerte de Antero Martín, un ganadero de Chozas de la Sierra fallecido en 1831 cuyos herederos pusieron en venta la totalidad de la ganadería. La transacción con los descendientes tuvo un montante final de siete mil quinientos reales por once toros, de casta jijona, que pasaron a formar parte de la vacada brava de Julián de Fuentes ${ }^{43}$.

Sin embargo, la muerte de Julián de Fuentes en 1836 dejó a Juan José como único valedor de la camada. Pero este no poseía ni el ímpetu ni el interés de negocio en torno a la ganadería taurina de su padre, algo que se hizo palpable a partir de 1834, aunque sí que supo gestionar mejor la cabaña ganadera.

\subsection{El ocaso ganadero: el modelo rentista de Juan José de Fuentes (1836-1852)}

La formación elitista de Juan José de Fuentes hizo atar sus decisiones en la búsqueda de intereses comunes junto a otros ganaderos, especialmente aquellos que poseían algún título nobiliario, como $\mathrm{M}^{\mathrm{a}}$ de la Paz Silva, descendiente de los condes de Salvatierra de Álava, que poseía una amplia ganadería de lidia ${ }^{44}$. Así, como parte de estas relaciones, se dio la corrida de toros el 29 de mayo de 1837 en la antigua plaza de toros de Madrid, la de la Puerta de Alcalá, derribada a comienzos de la década de 1870 con motivo de las obras del Ensanche ${ }^{45}$.

Consolidada ya su imagen como ganadero de lidia, Juan José de Fuentes comenzó a aprovechar la coyuntura del país en favor de su negocio. Al igual que había hecho su padre durante el período de la desamortización de Godoy en 1798 y la Guerra de la Independencia en 1808, buscó aumentar su volumen de superficie pratense a través de la desamortización promulgada por Mendizábal en 1836. Como bien había hecho su padre en los dos períodos desamortizadores anteriores, Juan José aprovechó también la ocasión para invertir su capital en las ventas públicas de suelo. Las compras, en este caso, se dieron a través de la adquisición de bienes eclesiásticos ${ }^{46}$ en las fincas cercanas de Moralzar-

43. AHPC, leg. 35-7.

44. López Izquierdo, F., "Ganaderos de bravos naturales o vecinos de Madrid (16071874)", Anales del Instituto de Estudios Madrileños 24, 1987, pp. 175-200.

45. López Izquierdo, F., Madrid y sus plazas de toros, Madrid, La Librería, 2000, pp. 8-34.

46. $A H P C$, leg. 48-2. La compra de estas fincas, que se encontraban a la vera de la sierra de Guadarrama, contenía el sustento de pastos para alimentar al amplio ganado bovino. Aun- 
zal, donde ya estaba establecida la ganadería. Asímismo, aprovechó la venta para comprar fincas en otros términos municipales vecinos como Becerril de la Sierra, Navacerrada y Mataelpino, bienes en su mayoría procedentes de la desamortización eclesiástica ${ }^{47}$.

Además de invertir en terrazgos, puso en marcha una política de cría de ganado cada vez más controlada, especialmente a partir de la contratación de dos ganaderos experimentados como ayudantes directos del todavía dirigente de la cabaña, Antonio Balandín. Así, Nicasio Morales y Manuel Segovia formaron parte de la ganadería desde el año 1834 al menos hasta mediados de la década de 1840, cuando dejaron de emitir sus libros de cuentas sobre las tareas que desarroIlaban, aunque es de suponer que se mantuviese al menos alguno de ellos hasta la venta final de la cabaña. A través del estudio de sus cuadernos de cuentas se puede conocer el salario medio su labor en la zona, que se estipulaba -siempre según su rango- entre los mil quinientos reales que se pagaban a algún pastor menor como Ramón González, hasta los más de seis mil que percibía Antonio Balandín por su labor como mayoral de la ganadería ${ }^{48}$. A menudo, tal y como demuestra la documentación, estos "libros de cuentas" de los pastores incluían las cantidades a cobrar y, también, las que debían pagar en concepto de créditos a la ganadería. Dichas cantidades, generalmente similares, proporcionaban al fin de año un pequeño superávit que no sobrepasaba los quinientos reales.

Tabla 1. Ventas Mulares de la Ganadería Fuentes (1834-1839). Tabla elaborada a partir de la documentación archivística. AHPC, leg. 35-5.

\begin{tabular}{|c|c|c|}
\hline Año & $\mathbf{N}^{\mathbf{0}}$ Mulas Vendidas & Cantidad Anual Ventas \\
\hline 1834 & 30 & 52.852 reales \\
\hline 1835 & 17 & 36.150 rs. \\
\hline 1836 & 21 & 43.725 rs. \\
\hline 1837 & 11 & 24.500 rs. \\
\hline 1838 & 16 & 36.325 rs. \\
\hline 1839 & 9 & 19.950 rs. \\
\hline
\end{tabular}

que años después le serían reclamadas por los estamentos eclesiásticos, las propiedades se mantuvieron bajo la propiedad de la familia Fuentes hasta finales del XIX.

47. AHPC, leg. 48-2.

48. A menudo, tal y como demuestra la documentación, estos "libros de cuentas" de los pastores incluían las cantidades a cobrar y, también, las que debían pagar, en concepto de créditos a la ganadería. Dichas cantidades, generalmente similares, proporcionaban al fin de año una pequeña cantidad económica de ganancia, que no sobrepasaba los quinientos reales. AHPC, leg. 35-9. 
Una de las medidas tomadas por estos nuevos gestores fue la evolución a la explotación de ganado de otras especies, no solo bovinos y ovinos, sino también mulares. La compraventa de la cabaña a partir de estos provocó un amplio aumento en la rentabilidad a partir de la mitad de la década de 1830. La documentación demuestra cómo Juan José de Fuentes se especializó, además de en la cría de ganado bovino, en la venta de mulas cerriles, muy necesarias para la labor agraria. Si bien lo más típico fue la venta directa de estos animales a diferentes interesados previo pago de un precio acordado, la ganadería Fuentes también puso en práctica la técnica de arrendamiento, con duración de un año ${ }^{49}$.

La rentabilidad de estas ventas fue decreciendo gradualmente, conforme su volumen disminuía. Sin embargo, el sistema de pago de las mulas se mantuvo en el tiempo durante los años, en parte gracias a las facilidades crediticias prestadas por la ganadería. La permeabilidad de los sistemas hizo que anualmente hubiese al menos una docena de deudores, que proporcionaban un capital medio de veinte mil reales cada año.

Tras esta actividad, durante los años centrales de la década de 1840, Juan José puso en marcha un plan sostenido de venta de sus reses de lidia. La bibliografía, amparada en fuentes de archivo, señala una bajada en los precios de venta de los toros, algo que hacía mucho menos rentable la ganadería. Ante este panorama, el ganadero de origen riojano decidió vender paulatinamente sus ejemplares a otros criadores interesados, limitando cada vez más su venta a los eventos taurinos y siguiendo la tendencia general de otros grandes ganaderos ${ }^{50}$.

A pesar de ello, Juan José de Fuentes mantuvo el ritmo de ventas a las principales plazas españolas. El coso de Bilbao, en junio de 1842, compró cuatro toros de la ganadería por doce mil reales; en julio de 1845 la plaza de Bilbao hizo lo propio con otros seis por 15.600 reales; y en 1846, la plaza de toros de Madrid y la de Almagro firmaron sendos contratos para comprar doce y seis toros respectivamente, que serían lidiados a lo largo del año. Sin embargo, a pesar de que la fama de su ganadería le permitía firmar contratos de venta, el precio a pagar era cada vez más bajo: en estas dos últimas transacciones, no superaba los 2.500 reales por cabeza ${ }^{51}$.

Este descenso en los precios coincidió con la falta de ímpetu sobre la actividad ganadera en Juan José de Fuentes y su creciente espíritu emprendedor en

49. $A H P C$, leg. 35-5.

Existen al menos más de una docena de contratos de arrendamiento de estos animales por parte del ganadero de origen riojano a pequeños propietarios, quienes se comprometen al pago de una cantidad previamente acordada, como también a un recargo en su contra en caso de faltar al pago.

50. López Martínez, A. L., El mercado taurino..., pp. 405-415.

51. Este decrecimiento en los precios ha quedado constatado con los principales estudios generales del mercado ganadero. Ibidem, pp. 415-421. 
otros sectores, como la banca o la política. Todo ello desembocó en la venta en 1847 de más de la mitad de la vacada joven de la ganadería Fuentes: cincuenta y una reses de cría y cuarenta y una reses bravas, siendo el comprador el también ganadero Cipriano Martínez, natural de Galapagar, en las estribaciones de la sierra de Guadarrama. El precio convenido entre los ganaderos fue el de cuatrocientos reales para los ejemplares mansos y de quinientos para los novillos jóvenes ${ }^{52}$. Aunque la ganadería mantenía todavía un amplio número de bóvidos, esta decisión suponía la extinción futura de la cabaña, así como la decisión firme de poner en oferta la totalidad de sus toros de lidia.

Tras esta venta, algunos otros interesados se hicieron eco de la situación de la ganadería y decidieron aprovechar la coyuntura. En 1849, la plaza de toros de Ronda compró dieciséis toros de la ganadería por 40.160 reales de vellón, para que fueran traídos en los "días gordos" 53 de la plaza. Algo parecido ocurriría solo un año más tarde, cuando José Campos, presidente de la Junta de beneficencia del Real Hospital de Valencia, adquirió doce reses bravas por un montante total de 32.400 reales.

TABLA 2. Número de ventas y rentabilidad media de la Ganadería Fuentes (1842-1852). Tabla elaborada a partir la documentación contractual de la ganadería con diferentes representantes de ganaderías y plazas de toros.

AHPC, leg. 36-1 y 36-2.

\begin{tabular}{|c|c|c|c|}
\hline Año & Reses bravas vendidas & Cantidad total apercibida & Precio medio por cabeza \\
\hline 1842 & 4 & 12.000 reales & 3.000 reales/unidad \\
\hline 1845 & 6 & $15.600 \mathrm{rs}$. & $2.600 \mathrm{rs} . / \mathrm{ud}$. \\
\hline 1846 & 18 & $45.600 \mathrm{rs}$. & $2.533 \mathrm{rs.} / \mathrm{ud}$. \\
\hline 1847 & 41 & $20.500 \mathrm{rs}$. & $500 \mathrm{rs} . / \mathrm{ud}$. \\
\hline 1848 & 18 & $45.000 \mathrm{rs}$. & $2.500 \mathrm{rs} . / \mathrm{ud}$. \\
\hline 1849 & 28 & $72.560 \mathrm{rs}$. & $2.591 \mathrm{rs} . / \mathrm{ud}$. \\
\hline 1850 & 12 & $32.400 \mathrm{rs}$. & $2.700 \mathrm{rs} . / \mathrm{ud}$. \\
\hline 1852 & 7 & $11.900 \mathrm{rs}$. & $1700 \mathrm{rs} . / \mathrm{ud}$. \\
\hline
\end{tabular}

El último de los movimientos previos a la desaparición de la ganadería Fuentes fue la compra de siete toros de lidia en mayo de 1852 a Ventura Díaz, un ganadero cercedeño. Aunque en un principio el precio por cada uno de ellos se

52. De esta venta se deducen claramente las intenciones de Juan José de Fuentes, que supondría pocos años después la venta total de la ganadería.

53. Este término es utilizado en las cláusulas del contrato. AHPC, leg. 36-1, Doc. 9. 
fijó en mil seiscientos reales y varios intereses sobre la futura venta a las plazas, ambos ganaderos renegociaron el contrato, pasando a ser mil setecientos reales el precio en metálico estipulado para cada bóvido ${ }^{54}$.

Es difícil de entender este movimiento de Juan José cuando el negocio había decaído tanto durante la última década. Sin embargo, este paso tuvo más que ver con un plan a corto plazo: el de liquidar su cabaña ganadera para verter así sus intereses sobre otros objetivos empresariales y políticos ${ }^{55}$. En 1852, recibió una oferta de compra de su ganadería por parte de Vicente Martínez, un santanderino neófito en el oficio que acabaría creando una de las dinastías ganaderas más importantes de las que ha habido afincadas en la sierra madrileña ${ }^{56}$.

La venta, que se cifró en 275.000 pesetas, le reportaría un amplio beneficio al comprador, pues supo manejar su vacada de manera magistral durante las últimas décadas del siglo XIX ${ }^{57}$. Así, el 28 de septiembre de 1852 se hacía cargo de ciento cincuenta y un toros de lidia, doscientas sesenta vacas y doce cabestros.

Coincidencia o no, Juan José vendió su ganadería de lidia en 1852, un año antes de que se promulgaran los primeros estatutos nacionales que regían el espectáculo. A partir de este momento, las pautas de control de las fiestas fueron cada vez más exigentes y la competencia ganadera más grande. Aunque seguía

54. AHPC, leg. 36-2. Doc. 1-4. La compra a Ventura Díaz era un movimiento de Juan José de Fuentes para hacer frente a otros compromisos adquiridos con empresarios durante los años anteriores.

55. Ya desde mediados de la década de 1830, Juan José de Fuentes comienza un proceso de inversión en distintas sociedades y empresas de todo tipo, que tendrá mucha más fuerza en las dos décadas siguientes.

De la misma manera, el de ascendencia riojana decidirá tomar parte en el proceso político de reciente creación, concretamente a partir de 1847, cuando formó parte de la Alcaldía Constitucional de Madrid; y especialmente a partir de 1854, momento en el que se convirtió en candidato a Cortes, siendo elegido en las elecciones de 1863. AHPC, leg. 55-2.

56. Vicente Martínez compuso una de las grandes ganaderías de la segunda mitad del siglo XIX, estableciéndose en una finca conocida como "El Soto", entre Colmenar Viejo y Moralzarzal, muy cerca de donde se encontraba la ganadería Fuentes. La bravura de los toros del santanderino le procuró amplia fama en el panorama nacional, consiguiendo incluir su hierro como uno de los más reconocidos y deseados en las plazas españolas. En el último cuarto de siglo, ante la aparición de cada vez más firmas ganaderas, fue perdiendo importancia, teniendo que adoptar técnicas de crianza para preservar la casta y bravura de las reses. Su muerte provocó la herencia de su yerno Luis Gutiérrez, quien, ante la pérdida de consistencia de la ganadería, decidió cruzar a sus reses con la casta vazqueña. Shubert, A., A las cinco de la tarde. Una historia social del toreo, Sevilla, Turner y Real Maestranza de Caballería de Ronda, 2002, pp. 48-55.

57. $A H P C$, leg. 48-5.

Tal y como reflejan las crónicas recogidas por Adrian Shubert, la ganadería de Vicente Martínez sostuvo una gran imagen de bravura. Además, su amistad con algunos toreros como "Joselito", convirtió a sus reses en predilectas en cada corrida. Shubert, A., A las cinco..., op. cit., pp. 48-52. 
predominando la rentabilidad económica por manos privadas, los estamentos públicos gubernamentales cada vez procuraban regularizar más el espectáculo y controlar así los posibles problemas que pudieran surgir a través de ellos, al ver en esto un espectáculo de masas que podría ocasionar distintos percances sociales y políticos ${ }^{58}$.

Además, el prestigio social de los ganaderos de principio de siglo, su importancia en los carteles y su renombre entre el pueblo, habían cedido paso en favor del de los toreros y sus apoderados. Los ganaderos eran, a mitad de siglo XIX, empresarios que buscaban una máxima rentabilidad a un negocio que, de por sí, debía ser visto a largo plazo para encontrar réditos ${ }^{59}$.

\section{Conclusiones}

Ha quedado demostrado que, hasta el siglo XVIII, los festejos en los que participaban estos animales se trataban de simples juegos y representaciones que carecían del control y la profesionalización suficiente en todos sus aspectos: desde el lugar (plazas mayores, etc.) hasta los participantes (toreros y rejoneadores) pasando por los intermediarios y proveedores (caso de los promotores y ganaderos). Como se ha visto, es a partir de mediados del siglo XVIII cuando los "toros" se constituyeron como el espectáculo que hoy en día se conoce ${ }^{60}$. Poco a poco, fue formándose todo un ceremonial basado en unas pautas indelebles, concluyendo con el devenir de la tauromaquia en un espectáculo de masas de carácter artístico.

En un momento de transformación y profesionalización en el ambiente taurino, Julián de Fuentes supo ver una oportunidad de negocio en la cría de toros de lidia. Lejos de ser un pionero en la tarea, se sumó a las casi cuatro decenas de comerciantes que habían apostado por el oficio durante los últimos años del $\mathrm{XVIII}{ }^{61}$. Aunque el proceso de cría se prolongaba durante varios años, a principios de siglo la ganadería Fuentes ya poseía una amplia cabaña bovina que le permitió granjearse un nombre en la fiesta nacional.

Es evidente que la inestabilidad política nacional afectó y mucho al fenómeno taurino. No es difícil de entender que, en momentos en los que la coyuntura socioeconómica no era estable y el país estaba muy dividido políticamente, no era tampoco el momento más propicio para realizar ningún tipo de festejo. No obstante, tras la restitución de Fernando VII, la industria de la tauromaquia tuvo

58. AHPC, leg. 48-5.

59. López Martínez, A. L., Ganaderías de lidia..., 85-103.

60. Álvarez Santaló, L. C., "Diversión, espectáculo y corridas de toros en el siglo XVIII. Una esquina moral de la llustración española", Revista de Estudios Taurinos 1, 1994, pp. 93114.

61. López Martínez, A. L., Ganaderías de lidia..., pp. 108-116. 
un ascenso sin parangón en todo el territorio nacional. Estos espectáculos se convirtieron en elementos básicos de la tradición popular, creando por primera vez una cultura de entretenimiento de masas. Junto con la profesionalización del arte, los réditos económicos también se hicieron cada vez mayores.

Esto se tradujo en la industria ganadera de lidia en un incremento del precio de ganado bravo, situación que se mantuvo hasta la década de 1830, momento en el que los contratos de venta de las ganaderías fueron descendiendo. Una de las múltiples causas fue, sin lugar a dudas, la mejora en la red vial y, sobre todo, la aparición a mediados del siglo XIX de una red ferroviaria cada vez más consistente, que permitía desplazar reses bravas de zonas alejadas de la capital y viceversa para las festividades taurinas, permitiendo a los Fuentes alcanzar otros mercados ${ }^{62}$.

La familia Fuentes no es, pues, un ejemplo de un ganadero de lidia típico del siglo XIX. Sus ámbitos empresariales, muy lejanos del requerimiento que atañía la cría del ganado de lidia, son los propios de una clase social de origen humilde que, tras haber hecho fortuna a través del intercambio comercial con las provincias orientales de Ultramar, vio en la actividad taurina una forma de consecución de prestigio más social que económico ${ }^{63}$.

Tanto Julián como Juan José de Fuentes se convirtieron en ganaderos más por la honra y fama que proporcionaba la aparición en los carteles de las tauromaquias que por una verdadera vocación económica. No hay mayor prueba del poco interés que tuvo Juan José de Fuentes que la venta en 1852 de la ganadería a Vicente Martínez, tras haber creado la familia de origen riojano una cabaña estable y potente de la que luego disfrutaría el comprador ${ }^{64}$. Se puede afirmar que, como queda constancia tras el análisis de la documentación, la estabulación nunca fue un fin para los Fuentes, sino que más bien fue un medio para conseguir aquello que les interesaba en cada momento: en las primeras décadas, fama y prestigio; en la última década, la de 1840, se convirtió en un negocio rentable en lo económico que le proporcionó una serie de contactos empresariales y políticos de los que disfrutaría pocos años después ${ }^{65}$.

62. Rueda Hernanz, G. España 1790-1900: sociedad y condiciones económicas, Madrid, Istmo, 2006, pp. 99-105.

63. López Martínez, Antonio L., Ganaderías de lidia..., pp. 126-133. Como apuntan algunos autores, no se trata del único en haber llevado a cabo este proyecto. La búsqueda de reconocimiento público en el status social es un factor fundamental para entender los comportamientos de la sociedad.

64. AHPC, Leg. 48-5.

65. Al vender la ganadería a Vicente Martínez, Juan José de Fuentes comenzó su carrera como político. Formó parte de la Alcaldía Constitucional de Madrid en 1853, para después conseguir un acta como diputado en las Cortes Nacionales. En 1864 se apartó del servicio público para centrarse en sus negocios privados, entre los que destacó su papel como consejero del Banco de España. 
Es una verdadera lástima el no haber podido encontrar una documentación más amplia sobre la ganadería Fuentes. Como apuntó hace algunos años López Martínez ${ }^{66}$, sería interesante estudiar este otro fenómeno: el de los ganaderos llegados a la profesión por la seducción producida por los réditos sociales más que por las ventajas puramente económicas. A pesar de la dificultad que entraña su estudio -en primer lugar, por la falta de documentación- es necesario llevar a cabo un trabajo que desgrane los verdaderos motivos del comportamiento de los estancieros durante el desarrollo de la industria taurina. El de la familia Fuentes es, pues, un caso claro de criadores por interés social más que económico, un avatar paradigmático dentro de la evolución de la ganadería de lidia sobre el que creemos haber aportado un halo de conocimiento.

\section{Bibliografía}

Amigo Vázquez, L., "El escenario de las fiestas taurinas. La Plaza Mayor como 'negocio' en la época moderna", Revista de Estudios Taurinos 24, 2008, pp. 54-148.

Álvarez Santaló, C. L., "Diversión, espectáculos y corridas de toros en el siglo XVIII. Una esquina moral de la Ilustración española". Revista de Estudios Taurinos 1, 1994, pp. 93-114.

Buenestado, B., "Urbanismo y plazas de Toros", PH: Boletín del Instituto Andaluz de Patrimonio Histórico 49, 2004, pp. 39-45.

Cabrera Bonet, R., "La iniciativa empresarial privada en el devenir del festejo madrileño del siglo XVIII", en García-Baquero González, A. y Romero de Solís, P. (coord.), Fiestas de toros y sociedad: actas del Congreso Internacional celebrado en Sevilla del 26 de noviembre al 1 de diciembre de 2001, Sevilla, Fundación Real Maestranza de Caballería de Sevilla, 2003, pp.159-194.

Caro Baroja, J., La hora navarra del XVIII (personas, familias, negocios e ideas). Pamplona, Comunidad Foral de Navarra y Servicio de Cultura Instituto Príncipe de Viana, 1969.

Corral López, G., "Fuero de Valdezcaray: cinco siglos de privilegios (13121837)", Boletín A.R.G.H. 4, 2012, pp. 9-28.

Cruz Valenciano, J., Los notables de Madrid. Las bases sociales de la revolución liberal española. Madrid, Alianza, 2000.

García-Baquero González, A., "Fiesta ordenada, fiesta controlada: las tauromaquias como intento de conciliación entre razón ilustrada y razón taurina", Revista de Estudios Taurinos 5, 1997, pp. 13-52.

66. López Martínez, A. L., "Ganadería de lidia y ganaderos...", pp. 103-133. 
García-Baquero González, A. y Romero de Solís, P., Fiestas de toros y sociedad: actas del Congreso Internacional celebrado en Sevilla del 26 de noviembre al 1 de diciembre de 2001, Sevilla, Fundación Real Maestranza de Caballería de Sevilla, 2003.

González Alonso, N. y Sánchez Gómez, M. A., "De la Sierra de la Demanda a la Corte. Un estudio de caso de la integración de las hidalguías antiguorregimentales en el sistema liberal", XVI Congreso de la Asociación de Historia Contemporánea, 2018. (Pendiente de publicación).

Guillaume-Alonso, A., "Las fiestas de toros en el Madrid crepuscular de Carlos II. Crónica de una evolución imparable", Revista de Estudios Taurinos 28, 2010, pp. 81-109.

Iriarte Goñi, I., "Common lands in Spain, 1800-1995: Persistence, Change and Adaptation", Rural history 13 (1), 2002, pp. 19-38.

Iribarren Rodríguez, J. M., "Los toros de Navarra", Príncipe de Viana 32, 1948, pp. 361-406.

López Izquierdo, F., "La Real Vacada Brava de Aranjuez: los toros más veces lidiados de Madrid", Villa de Madrid: revista del Excmo, Ayuntamiento 49, 1975, pp. 67-75.

López Izquierdo, F., "Ganaderos de bravos naturales o vecinos de Madrid (16071874)", Anales del Instituto de Estudios Madrileños 24, 1987, pp. 175-200.

López Izquierdo, F., Historia del toro de lidia: de la prehistoria hasta nuestros días, Madrid, Agualarga, 1996, pp. 105-123.

López Izquierdo, F., Madrid y sus plazas de toros, Madrid, La Librería, 2000, pp. 8-34.

López Martínez, A. L., "La cría del ganado de lidia y la gran explotación agraria en Andalucía (s. XVIII-XIX)". Estudios Agrosociales y Pesqueros 184, 1998, pp. 137-158.

López Martínez, A. L., Ganaderías de lidia y ganaderos. Historia y economía de los toros de lidia en España. Sevilla, Fundación Real Maestranza de Caballería de Sevilla y Universidad de Sevilla, 2002.

López Martínez, A. L., "De las vías pecuarias a los ferrocarriles. El transporte de toros de lidia en España (siglos XVII-XX)", Revista de Estudios Taurinos 22, 2006, pp. 249-272.

López Martínez, A. L., El mercado taurino en los inicios de la tauromaquia moderna. Sevilla, Fundación Real Maestranza de Caballería de Sevilla y Universidad de Sevilla, 2013.

López Martínez, A. L., "Toros y urbanismo en España: plazas mayores, correderas y toriles", Revista de Estudios Taurinos 35, 2014, 15-58.

López Martínez, A. L., "Fiestas de toros: ocio y negocio". Andalucía en la Historia (Dossier) 48, 2015, pp. 14-20. 
López Martínez, A. L., La ganadería de lidia en España. Historia, Geografía y Empresa, Sevilla, Ed. Propia, 2018.

MacClancy, J., "Falsificaciones inglesas del género, corridas y el Estado", en Fernández de Rota y Monter, J. A. (coord.), Las diferentes caras de España: perspectivas de antropólogos extranjeros y españoles, La Coruña, Universidad de la Coruña, 1996, pp. 125-137.

Moreno Fernández, J. R., "Las áreas rurales de montaña en la España del siglo XVIII. Las sierras del Sur de La Rioja", Revista de Historia Económica 19 (extra 1), 2001, pp. 66-79.

Rueda Hernanz, G., España 1790-1900: Sociedad y condiciones económicas. Madrid, Istmo, 2006.

Sánchez-Ocaña Vara, A. L., "Las prohibiciones históricas de la fiesta de los toros", Arbor 189 (763), 2013, a074. http://doi.org/10.3989/arbor.2013.763n5011.

Shubert, A., "En la vanguardia del ocio mercantilizado de masas: La corrida de toros en España, siglos XVIII y XIX", Historia Social 41, 2001, pp. 113-126.

Shubert, A., "El toreo en la historia española", Revista de Estudios Taurinos 28, 2010, pp. 15-41.

Shubert, A., A las cinco de la tarde. Una historia social del toreo, Madrid, Turner y Real Maestranza de Caballería de Ronda, 2002.

Uría, J., "El nacimiento del ocio contemporáneo", Historia Social 41, 2001, pp. 65-68.

Valle Buenestado, B., "Urbanismo y plazas de Toros", PH: Boletín del Instituto Andaluz de Patrimonio Histórico 49, 2004, pp. 39-45.

\section{Fuentes Archivísticas}

Archivo General de Simancas, Sección Catastro de Ensenada, Respuestas Generales de Valgañón, Leg. 057, 614-673. http://pares.mcu.es/Catastro/ (2803-2019).

Archivo Histórico Provincial de Cantabria, Sección Caja Cantabria, Casa Fuentes. Legajos: 35, 36, 47, 48, 60. 